\title{
Digital Image Correlation applied to in situ evaluation of surface cracks upon curing of $\mathrm{MgO}$-containing refractory castables
}

\author{
V. F. Sciuti ${ }^{a}$, F. Hild ${ }^{b}$, V.C. Pandolfelli ${ }^{a, c}$, T. Santos ${ }^{a}$, B. Smaniotto ${ }^{b}$ and R.B. Canto ${ }^{a, c}$ \\ ${ }^{a}$ Federal University of São Carlos, Graduate Program in Materials Science and Engineering (PPGCEM), 13565-905, São Carlos-SP, Brazil \\ ${ }^{c}$ Federal University of São Carlos (UFSCar), Department of Materials Engineering (DEMa), 13565-905, São Carlos-SP, Brazil, Brazil \\ ${ }^{b}$ Université Paris-Saclay, ENS Paris-Saclay, CNRS, LMT - Laboratoire de Mécanique et Technologie, 94235 Cachan, France
}

\section{ARTICLE INFO}

\section{Keywords:}

crack network

$\mathrm{MgO}$ hydration

damage

ceramic processing

\begin{abstract}
A B S T R A C T
$\mathrm{MgO}$ particles are added to high-alumina castables to provide in situ spinel formation at high temperatures. However, the $\mathrm{MgO}$ hydration upon curing may damage the material because of localized volumetric expansion. Usually, the damage is evaluated by the ex situ overall measurement of Young's modulus changes during processing via Impulse Excitation Techniques. In this paper, an experimental setup was designed to use Digital Image Correlation (DIC) as an in situ alternative to evaluate the damage. Tomographic scans highlighted that all cracks initiated on the sample surfaces, and propagated in the bulk in an intergranular mode. Crack initiation and growth were assessed, for different temperatures, via Surface Crack Density (SCD) measurements, and Mean Crack Opening Displacement (MCOD) fields. They provided important insights into heterogeneous expansion phenomena and crack network quantification; for example, the SCD flattened out while the overall damage was still increasing. The results attested the usefulness of DIC for in-situ quantification of ceramics cracking during the processing.
\end{abstract}

\section{List of abbreviations and symbols}

BR: Bar Resonance

CT: Computed Tomography

DIC: Digital Image Correlation

IET: Impulse Excitation Technique

MCOD: Mean Crack Opening Displacement $[\mu \mathrm{m}]$

ROI: Region Of Interest

RVE: Representative Volume Element

SCD: Surface Crack Density [\%]

ZOI: Zone Of Interest

囚: symmetrized tensorial product

$A$ : factor to account for expansion strains before cracking

$D_{e}(t)$ : number of damaged elements

$\boldsymbol{\epsilon}$ : strain tensor

$\epsilon_{1}^{*}:$ maximum principal strain threshold

$\overline{\boldsymbol{\epsilon}}$ : mean strain tensor

$\sigma\left(\bar{\epsilon}_{1}\right)$ : standard deviation of the maximum principal strain

$E$ : Young's modulus [Pa]

$\phi^{2}$ : sum of squared differences

$f$ : reference image

$\Gamma_{e}$ : cracked surface

$g$ : deformed image

$\ell$ : element size $[\mu \mathrm{m}]$

$N_{e l}$ : total number of elements in the mesh

n: normal direction to the crack path

*Corresponding author

(0) vfsciuti@gmail .com (V.F. Sciuti)

ORCID(s): 0000-0002-3709-3189 (V.F. Sciuti); 0000-0001-5553-0066 (F. Hild); 0000-0002-1711-9804 (V.C. Pandolfelli); 0000-0002-6490-1049 (T. Santos); 0000-0002-9286-9912 (R.B. Canto) 
$\left|\Omega_{e}\right|$ : surface of element $e$

$s$ : curvilinear abscissa

$t$ : time [s]

u: displacement field

$v_{i}$ : unknown degrees of freedom

$\overline{\llbracket \mathbf{u} \rrbracket}$ : mean displacement jump vector

$\mathbf{x}$ : pixel position

\section{Introduction}

There is a growing trend among refractory ceramic producers and end-users to replace pre-shaped materials by castables, where the latter ones, besides being jointless, are also able to have their placing process robotized [1, 2]. High alumina refractory castables containing magnesia show advantages such as in situ spinel $\left(\mathrm{MgAl}_{2} \mathrm{O}_{4}\right)$ formation at temperatures above $1200^{\circ} \mathrm{C}$, which increases their resistance to basic slag corrosion and damage by thermal shock [3, 4]. The addition of small $\mathrm{MgO}$ particles, which are more reactive than coarse ones, leads to spinel formation at lower temperatures [5, 6]. However, $\mathrm{MgO}$ reacts with water during curing and drying of the castable, generating brucite $\left[\mathrm{Mg}(\mathrm{OH})_{2}\right]$ [7-9]. At the beginning of the hydration process, brucite closes pores in the ceramic matrix. The excess of brucite formation easily damages the material $[10,11]$. This damage depends on the $\mathrm{MgO}$ content of the castable composition, as well as the temperature and the relative air humidity [7-9].

The brucite formation induces high stress levels in the material matrix because of the significant difference between the specific volume of magnesia $\left(v_{\mathrm{MgO}}=0.283 \mathrm{~cm}^{3} \mathrm{~g}^{-1}\right)$ and brucite $\left(v_{\mathrm{Mg}(\mathrm{OH})_{2}}=0.471 \mathrm{~cm}^{3} \mathrm{~g}^{-1}\right)$ [12]. If the pores inside the sample are not large enough to accommodate the expansion, stresses are generated, and cracks may initiate and propagate when the castable strength is reached [13]. In an attempt to increase the mechanical strength of castables, methods to control such reactions have been developed to inhibit crack formation or hydration [10, 14].

The Bar Resonance (BR) technique [15] has been used to evaluate Young's modulus $(E)$ variations during curing and drying of $\mathrm{MgO}$-based castable refractories, which indirectly highlights $\mathrm{MgO}$ hydration and the mechanical damage caused by the reaction [11, 16, 17]. Additionally, the Impulse Excitation Technique (IET) [18] was applied to measure the damping caused by microstructural modifications of refractory castables after thermal shocks [19] and the Young's modulus of alumina castables [20].

An alternative route is provided by Digital Image Correlation (DIC). DIC a full-field displacement measurement technique, which has been utilized in many areas of mechanical and materials engineering [21-31]. DIC has, for instance, been used to evaluate the toughness of materials [21, 23, 24], to characterize refractories on a laboratory scale $[25,29,31]$, and to detect initiation and crack propagation $[22,26]$. The technique was also shown to be reliable for assessing physical and mechanical damage [32]. The evaluation of the drying process of concrete [33] and crack pattern formation during curing and drying of castable refractories [30] are examples in that area. DIC provides more detailed data about damage fields, and additionally, its in situ feature makes it easier to be used than the BR technique. Furthermore, the match between BR and DIC has already been demonstrated, as the decrease in Young's modulus was correlated with the increase in physical damage obtained via DIC [34].

In situ techniques such as DIC are particularly appealing because they preserve the processing conditions, such as temperature and relative air humidity, during tests. Besides, the measurements can be carried out with no operator interference, as the technique is fully automated when using climatic chambers, with no need to move the specimen from one piece of equipment to another. Considering the development of this methodology, stereo-DIC [35] may be applied not only for cube-shaped specimens but for different regions of the inner refractory lining of steel ladles, for example. Moreover, digital volumes reconstructed from tomography images may be used to study cracks not only on the surfaces but also in the bulk of the specimen by applying Digital Volume Correlation (DVC) [32].

This paper introduces the experimental setup used to apply the DIC technique for studying the crack network formation upon curing and drying of $\mathrm{MgO}$-containing refractory castables. DIC provided the damage process field data (i.e., surface crack network), whereas IET the overall damage estimate. Cube-shaped specimens with a size corresponding to an experimental Representative Volume Element (RVE) were tested and compared to bar-shaped ones. Furthermore, the cube-shaped samples were used to study the effect of temperature on brucite formation and damage evolution. 


\section{Material and Methods}

\subsection{Material}

High alumina refractory castables containing 6 wt.\% of caustic magnesia (98 w.t.\% $\mathrm{MgO}_{90}<33 \mu \mathrm{m} \mathrm{RHI} \mathrm{-}$ Magnesita, Brazil) and high specific surface area $\left(24.6 \mathrm{~m}^{2} \mathrm{~g}^{-1}\right)$ were formulated following the Alfred packing model with $q=0.26$ using tabular (Almatis, Germany) and reactive aluminas CL370 and CT3000SG as raw materials. A polycarboxylate ether-based dispersing agent (Castament ${ }^{\circledR}$ FS60, BASF, Germany) was added, and water was adjusted to provide $80 \%$ of initial flow under vibration [36]. The $\mathrm{Al}_{2} \mathrm{O}_{3}-\mathrm{MgO}$ castable formulation used in this study is reported in Table 1.

\section{Table 1}

Composition of the studied $\mathrm{Al}_{2} \mathrm{O}_{3}-\mathrm{MgO}$ based castables

\begin{tabular}{cc}
\hline Raw materials & [wt.\%] \\
\hline \hline Tabular alumina $(d \leq 6 \mathrm{~mm})$ & 81 \\
\hline Tabular alumina $(d<45 \mathrm{~mm})$ & 6 \\
\hline Reactive alumina $($ CL370) & 2 \\
\hline Reactive alumina (CT3000SG) & 5 \\
\hline Caustic magnesia & 6 \\
\hline Water & 5.1 \\
\hline Dispersant & 0.2
\end{tabular}

\subsection{Specimen production}

The the raw materials were mixed in a castable rheometer, with no preheating. They were homogenized for $10 \mathrm{~min}$ at room temperature $\left(25^{\circ} \mathrm{C}\right)$ and $50 \%$ relative air humidity. The content of water was set for a vibration flow of $80 \%$ (ASTM C1445-07 [37]). A vibrating table was used to cast the resulting mix into silicone molds $\left(150 \times 25 \times 25 \mathrm{~mm}^{3}\right)$ [Figure 1(a)], a typical size for IET specimens, and $70 \times 70 \times 70 \mathrm{~mm}^{3}$ for the cubic ones [Figure 1(b)]. The edge size of the cubes $(70 \mathrm{~mm})$ was chosen because it is more than ten times the average diameter of the largest aggregates $(\approx 6 \mathrm{~mm})$, which may provide an "experimental" representative volume element (RVE) [38]. The flexibility of the silicone helps the demolding process. After casting, the specimens and the mold were stored in an in-house developed climatic chamber, where the image acquisitions could be carried out. The specimens were demolded after three hours at $50{ }^{\circ} \mathrm{C}$ and $50 \%$ relative air humidity. They were subsequently prepared to provide a wide variety of gray levels for the DIC procedure, namely, two perpendicular faces of the cubic specimens and one face of the bar-shaped samples were speckled with black paint as the castable has a light and mat hue.

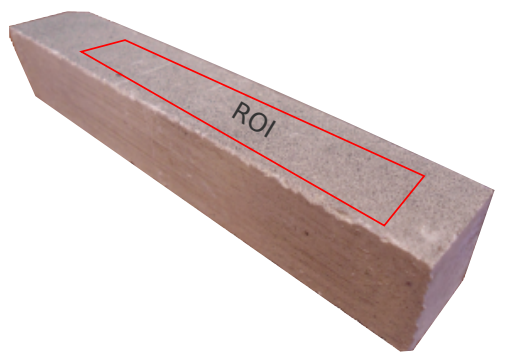

(a)

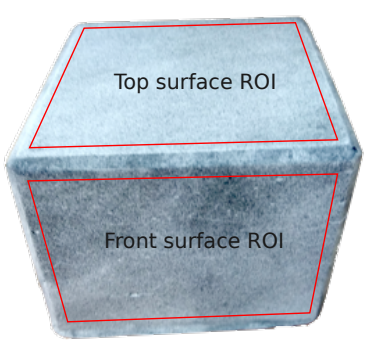

(b)

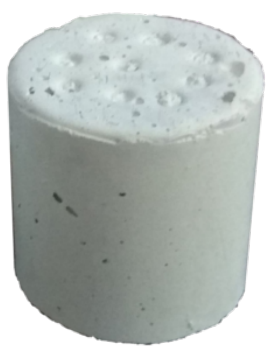

(c)

Figure 1: Fabricated specimens, namely, bars for IET (a), cubes for in situ DIC (b), and cylinder for CT scans (c). The Regions of Interest (ROIs) used in the DIC analyses are marked in red. (a) $25 \times 25 \times 150 \mathrm{~mm}^{3}$ bar (designation: $50 \mathrm{~T} 1 \mathrm{~b}$ ) for IET, ROI size $=14 \times 144 \mathrm{~mm}^{2}$ for DIC. (b) $70 \times 70 \times 70 \mathrm{~mm}^{3}$ cube (designation: $50 \mathrm{~T} 1 \mathrm{c} \mid \mathrm{ROI}$ size $\approx 60 \times 60 \mathrm{~mm}^{2}$ for DIC)

A cylinder (50 $\mathrm{mm}$ in diameter and $50 \mathrm{~mm}$ in height) was made following almost the same procedure as for the cubes and the bars [Figure 1(c)], apart from the fact that the mold was closed with a lid to obtain a smooth surface. 
Plastic tubes were assembled on the lid to enable for air extraction during casting. These tubes formed small cavities on the cylinder top surface.

Such axisymmetric geometry is more suitable for computed tomography as X-rays will traverse the same thickness for any angular position of the sample in front of the detector. Further, the diameter (i.e., $50 \mathrm{~mm}$ ) had to be reduced in comparison with the size of the cubes (i.e., $70 \mathrm{~mm}$ ) for the X-rays to traverse the sample and get a better signal to noise ratio for the selected source voltage, which was close to the maximum level of the scanner.

Three different sample geometries were fabricated. Each had to be made consistent with the experimental techniques that were conducted to analyze damage induced by curing. Consequently, quantitative comparisons between different results can only be carried for the same geometry. Conversely, in all three configurations, the same physical mechanisms drove the damage process (i.e., crack initiation and propagation), namely, microstructural changes within the refractory castable. However, the damage kinetics and extent may be different because of environmental and geometric differences.

\subsection{X-ray tomography}

Computed Tomography (CT) scans acquisitions were carried out using the X50-CT+ scanner (North Star Imaging, USA) located at LMT (ENS Paris-Saclay). The X-ray tube equipped with a W target was set to $200 \mathrm{kV}$ with a current of $360 \mu \mathrm{A}$, resulting in a power of $62 \mathrm{~W}$. A $0.3 \mathrm{~mm}$ thick copper filter was used to limit beam hardening. The volumes of the specimen were reconstructed using 1,200 radiographs that were acquired over one $360^{\circ}$ revolution. Each radiograph was obtained as an average of 30 frames to reduce acquisition noise. The result was 3D images with $1,000 \times 1,000 \times$ 1,000 voxel definition, and a resolution of $\approx 48 \mu \mathrm{m}$ per voxel. The specimen was kept at room temperature $\left(\approx 25^{\circ} \mathrm{C}\right)$ and room humidity (i.e., 40-50\%) for 13 days. CT scans were carried out 0, 4, 6, 8, 11 and 13 days after the specimen was exposed to room temperature and humidity.

\subsection{Climatic chamber}

The in-house climatic chamber was equipped with temperature and relative air humidity controllers, tempered glass windows, and high definition digital cameras to carry out acquisitions during the whole stages of curing and drying of refractory castables. A detailed sketch is shown in Figure 2.

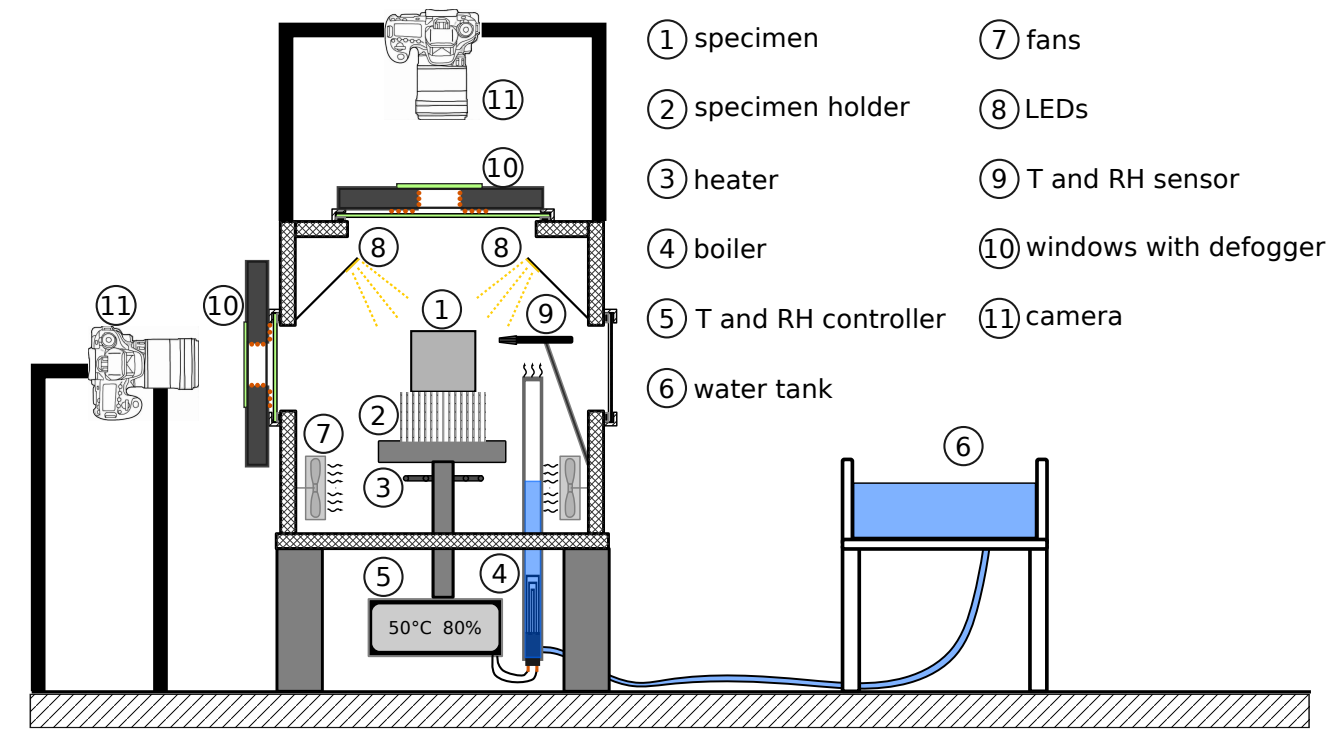

Figure 2: Schematic view of the experimental setup of the in-house made climatic chamber for monitoring $\mathrm{MgO}$ hydration via DIC analyses

Inside the chamber, the specimen (1) was placed on the tip of thin metal rods (2) to reduce specimen displacement constraints and ensure that all surfaces were in contact with moist air. An N322RHT device (Novus, Brazil), which is specific for confined environments, comprising a sensor (9) and controller (5), was used to record the temperature and relative air humidity inside the chamber. This controller was connected to a heater (electric resistance wire (3)) and a 
boiler (4). The former heats up the air and the latter boils the water used as moisture source. A tank (6) supplies the water to the boiler. Four fans (7) located at the bottom of the climatic chamber generated forced airflow that increased the temperature and humidity homogeneity inside the chamber. Glass windows were added to enable pictures of two of the specimen surfaces to be acquired, and LED lights 8 provided proper illumination. To avoid window condensation caused by water vapor, two defoggers 10 were inserted to heat them to temperatures five degrees Celsius above that inside the chamber. Two high definition (18 color Mpixel) Canon T5 digital cameras 11) equipped with Canon macro $100 \mathrm{~mm}$ lenses (Canon Inc., Japan) were used. The images were recorded every $10 \mathrm{~s}$ for the first 10 images, and every 30 min thereafter, with a $f / 2.8$ aperture and exposure time of $3 \mathrm{~s}$. The large exposure time was used to make a physical average of the changes in gray levels to mitigate heat haze effects [39].

Experiments using the bar-shaped specimens were carried out in an environment with $50 \%$ relative air humidity and $50^{\circ} \mathrm{C}$. Similarly, the experiments using the cube-shaped specimens were conducted at the same relative air humidity and two different temperature levels, namely, 50 and $70^{\circ} \mathrm{C}$ and were duplicated. The results of each imaged surface are presented and named by $\mathrm{F}$ (for the front surface), and $\mathrm{T}$ (for the top), see Figure 1, followed by the specimen shape and a number to distinguish duplicates. For example, the results of the second experiment carried out analyzing the front surface of the cube tested at $70^{\circ} \mathrm{C}$ are designated as $70 \mathrm{~F} 2 \mathrm{c}$ (i.e., temperature + surface + specimen number + specimen shape).

\subsection{DIC analyses}

DIC is classified into two different approaches, namely local and global. Let us consider a reference image $f$, and a deformed one $g$, i.e., images before and during loading. Each approach is based on the assumption that the gray level of every pixel $\mathbf{x}$ located in a sub-domain of the reference image $f$ is identical in the image $g$, but displaced by $\mathbf{u}$

$$
f(\mathbf{x})=g(\mathbf{x}+\mathbf{u}(\mathbf{x}))
$$

For local DIC, the image is partitioned into small subgroups of pixels called Zones of Interest (ZOI) and displacement $\mathbf{u}$ is measured at the center of each ZOI by, for instance, the maximization of the cross-correlation product [35, 40-42]. In global DIC, the displacement field $\mathbf{u}$ minimizes the gap $\phi^{2}$ to gray level conservation for all pixels located within the ROI

$$
\phi^{2}=\sum_{\text {ROI }}[f(\mathbf{x})-g(\mathbf{x}+\mathbf{u}(\mathbf{x}))]^{2}
$$

As such, this is an ill-posed problem [27]. To improve the conditioning of the system, some restrictions are made. For example, the kinematics of a group of pixels is regularized by expressing the sought displacement field $\mathbf{u}_{\text {DIC }}(\mathbf{x})$ as

$$
\mathbf{u}_{D I C}(\mathbf{x})=\sum_{i=1}^{N} v_{i} \Psi_{i}(\mathbf{x})
$$

in which $v_{i}$ are the unknown degrees of freedom, and $\boldsymbol{\Psi}$ are the selected vector fields (e.g., shape functions associated with finite element discretizations $[43,44])$. Using such methodology, the measured displacements are obtained as

$$
\left\{\boldsymbol{v}_{\mathrm{DIC}}\right\}=\underset{\{\boldsymbol{v}\}}{\arg \min } \phi^{2}(\{\boldsymbol{v}\})
$$

where $\left\{\boldsymbol{v}_{\text {DIC }}\right\}$ is the column vector that stores all amplitudes $v_{i}$. In the present paper, meshes made of 3-noded triangular elements were used to carry out DIC analyses [44].

\subsection{DIC-based quantification of crack networks}

The results provided by DIC that are reported in this paper are the Mean Crack Opening Displacement (MCOD) per element and the Superficial Crack Density (SCD). The former was calculated from the mean strain tensor estimated for each element (e) covering a domain $\Omega_{e}$. In the presence of cracks, the mean strain tensor is expressed as [45]

$$
\overline{\boldsymbol{\epsilon}}=\frac{1}{\left|\Omega_{e}\right|} \int_{\Omega_{e}} \boldsymbol{\epsilon}(\mathbf{x}) \mathrm{d} \mathbf{x}+\frac{1}{\left|\Omega_{e}\right|} \int_{\Gamma_{e}} \llbracket \mathbf{u}(\mathbf{x}) \rrbracket \bigotimes \mathbf{n}(\mathbf{x}) \mathrm{d} \mathbf{s}
$$


where $\llbracket \mathbf{u} \rrbracket$ denotes the displacement jump, $\mathbf{n}$ the normal to the cracked surface $\Gamma_{e}, \bigotimes$ the symmetrized tensorial product, $\boldsymbol{\epsilon}$ the strain tensor of the uncracked matrix, and $s$ the curvilinear abscissa along the crack path. In the following equations, it is assumed that the strain levels due to curing and drying are negligible with respect to the singular contribution provided by cracks. Consequently, the mean strain tensor becomes

$$
\overline{\boldsymbol{\epsilon}} \approx \frac{1}{\left|\Omega_{e}\right|} \int_{\Gamma_{e}} \llbracket \mathbf{u}(\mathbf{x}) \rrbracket \nabla \mathbf{n}(\mathbf{x}) \mathrm{d} \mathbf{s}
$$

The MCOD $\overline{\llbracket \mathbf{u} \rrbracket}$ per finite element is defined as

$$
\overline{\llbracket \mathbf{u} \rrbracket} \otimes \overline{\mathbf{n}}=\frac{1}{\left|\Gamma_{e}\right|} \int_{\Gamma_{e}} \llbracket \mathbf{u} \rrbracket \bigotimes \mathbf{n} \mathrm{d} \mathbf{s}
$$

where $\overline{\mathbf{n}}$ is the mean crack normal. Further, it is assumed that the main opening share is associated with the mode I regime

$$
\overline{\llbracket \mathbf{u} \rrbracket}=\llbracket u \rrbracket \overline{\mathbf{n}}
$$

such that $\overline{\mathbf{n}}$ then corresponds to the eigen direction associated with the average maximum principal strain $\bar{\epsilon}_{1}$. The latter is then related to the mean crack opening displacement (MCOD) $\overline{\llbracket u \rrbracket}$ by

$$
\left|\Omega_{e}\right| \bar{\epsilon}_{1}=\left|\Gamma_{e}\right| \overline{\llbracket u \rrbracket}
$$

It is worth noting that $\left|\Omega_{e}\right| /\left|\Gamma_{e}\right|$ scales with the element size $\ell$, provided only one crack is present in each element. This is likely to be true for small element sizes. Consequently, the MCOD is approximated by

$$
\overline{\llbracket u \rrbracket}=\ell \bar{\epsilon}_{1}
$$

The SCD was estimated by the ratio of the number of damaged elements to their total ones. To define damaged elements, an eigen strain threshold $\epsilon_{1}^{*}$ was defined. The latter is obtained by evaluating the standard deviation of the average maximum principal strain $\sigma\left(\bar{\epsilon}_{1}\right)$ for the first ten images, which were captured at the very beginning of the experiment with a time interval of $10 \mathrm{~s}$. As the images were recorded before crack initiation, $\sigma\left(\bar{\epsilon}_{1}\right)$ is associated with the experimental setup (i.e., fluctuations in lighting and acquisition noise of the camera sensors). $\sigma\left(\bar{\epsilon}_{1}\right)$ was then multiplied by a factor $A$ to account for the strains induced by the expansion during the brucite formation before the initiation of cracks.

In order to choose an appropriate constant $A$, different values were tested and the effects on SCD data at the very beginning of the experiments were investigated. Because SCD should be close to zero before crack initiation, it was chosen as the smallest factor that resulted in a mean SCD less than $1 \%$ for the 10 initial images. To reduce the user's influence on selecting $A$, additional research should be carried out. As the level of $\epsilon_{1}^{*}$ was set (for each experiment), the elements whose average maximum principal strain $\bar{\epsilon}_{1}$ was greater than $\epsilon_{1}^{*}$ were classified as damaged. The number of damaged elements $D_{e}(t)$ was then obtained as a function of time $t$, and then the superficial crack density (SCD) was calculated as

$$
\operatorname{SCD}(t)=\frac{D_{e}(t)}{N_{e l}}
$$

where $N_{e l}$ is the total number of elements in the mesh.

The DIC analyses were carried out with the Correli 3.0 code [46]. The element size for both samples was $\approx 800 \mu \mathrm{m}$ (or 16 pixels).

\subsection{Impulse Excitation Technique}

The Impulse Excitation Technique (IET) was used following the ASTM E1876 standard [18] to estimate the Young's modulus $E$ and, indirectly, the damage level caused by magnesia hydration. Two bar specimens were extracted from the climatic chamber and had their Young's moduli measured by intervals of $\approx 1 \mathrm{~h}$, while the other two bars were kept in the climatic chamber for image acquisition. The RFDA HT1600 device (IMCE Genk, Belgium) was used for this procedure. The excitation mode was defined as flexure. The bar specimens, specifically the region of harmonic nodes, were placed on polymeric wires. A microphone was positioned above and a pneumatic hammer below the bar, at the middle of its length. At least three pulses were captured before computing the value of Young's moduli. 


\section{Results and Discussion}

\subsection{Tomography scans}

It is possible to have an estimate of the distribution of aggregates in the specimen by visualizing the sagittal and coronal sections of the cylindrical specimen [Figure 3]. The constituents of the microstructure are distinguished by their respective density, which is represented by different gray levels, i.e., the voids and cracks are black, the matrix is gray and the alumina aggregates are white. Large aggregates are uniformly distributed in the specimen, which is

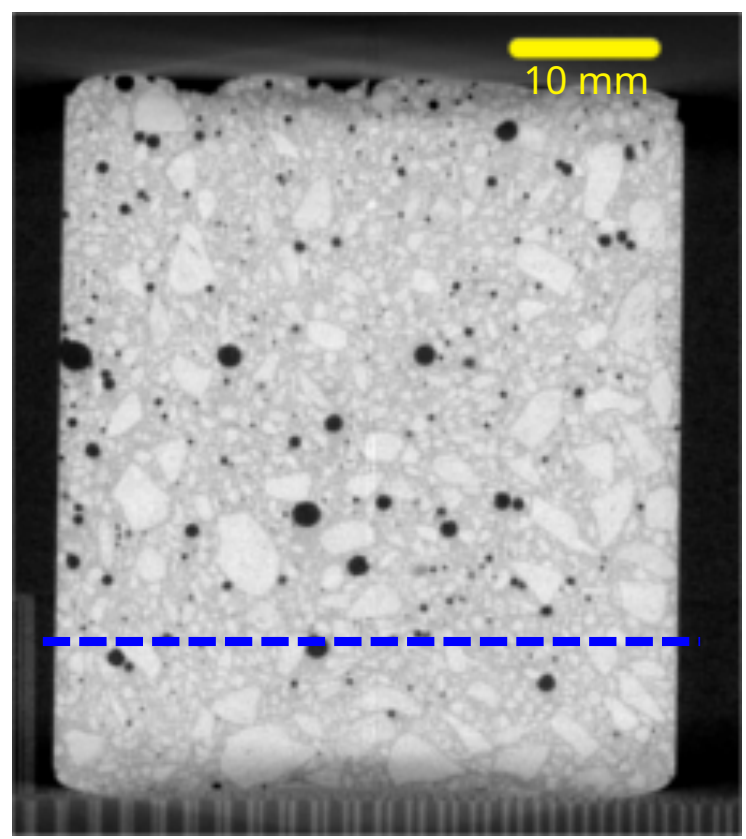

(a)

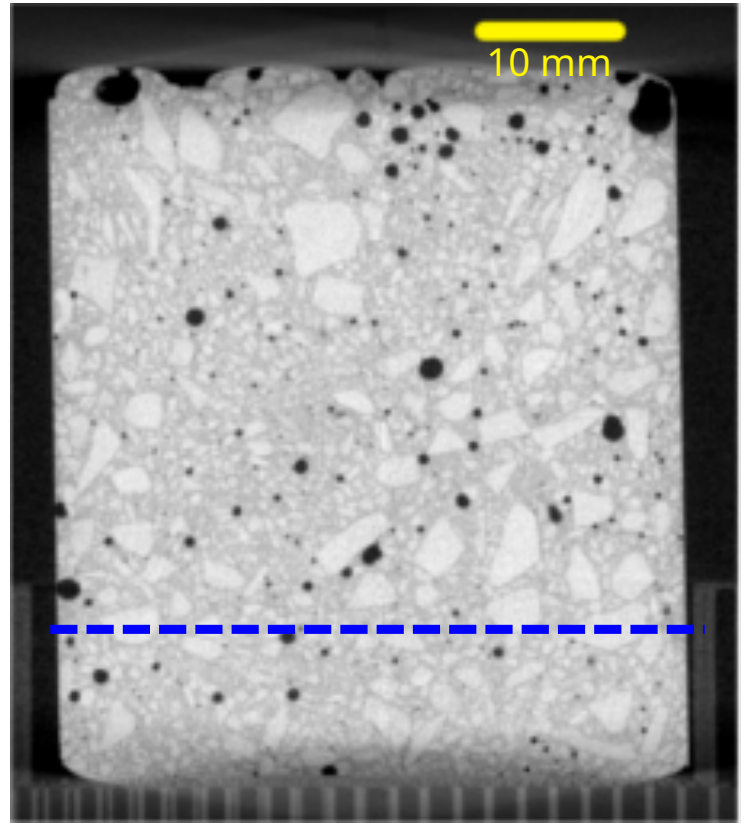

(b)

Figure 3: Sagittal and coronal sections of the CT volume for the first day of curing and drying. The blue dashed lines mark the position of the axial section shown in Figure 4

indicated by comparing sagittal, coronal and axial [Figures 3 and 4] sections.

Crack initiation and propagation for an axial section of the six CT scans extracted at $\approx 11 \mathrm{~mm}$ height of the cylindrical specimen is shown in Figure 4. The propagation of two main cracks is observed ex situ for the specimen kept at room temperature and room relative air humidity during 13 days after casting. The cracks depicted in transverse slices initiated on the cylinder surface, and both propagated toward the center axis. This observation validates using DIC to study the damage caused by $\mathrm{MgO}$ hydration (i.e., this technique is based on surface images where crack initiation originated). DVC [32] may also be applied to study the damage initiated on the surface and its propagation within the bulk of the specimen, although such analyses are not within the scope of the present paper

Another important piece of information obtained by observing the volumes is that the cracks propagated in the castable matrix in an intergranular manner. They do not start inside aggregates or cross them, which means that the DIC results may show regions with high maximum principal strains (i.e., cracks) among others with virtually zero strains (i.e., aggregates). This observation sheds some light on the likely relationship of the distribution of aggregates and crack networks. 

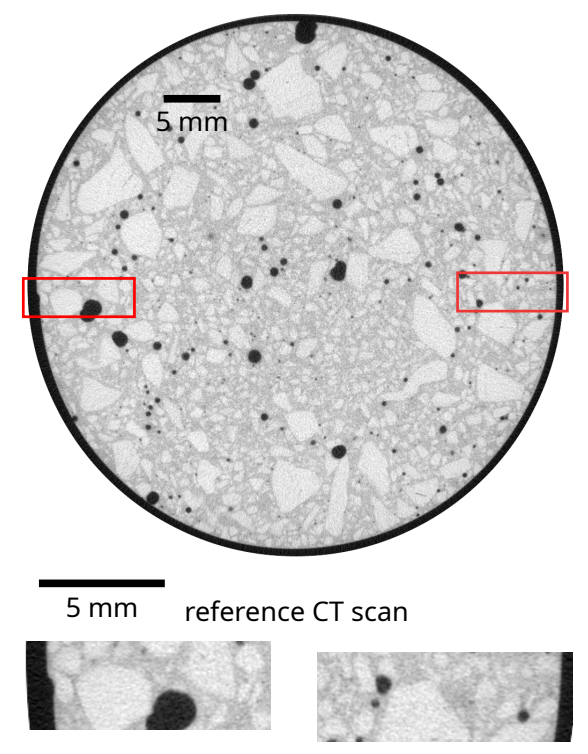

4 days
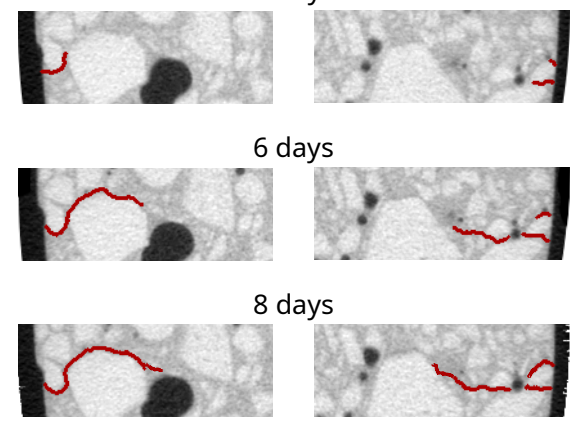

11 days

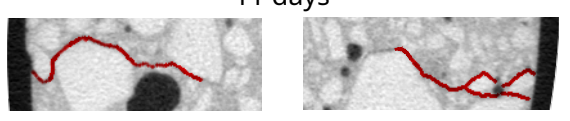

13 days

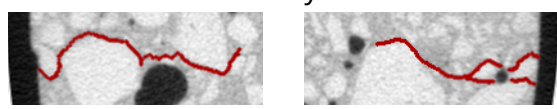

Figure 4: Axial section [see Figure 3] of the reconstructed volumes of a cylindrical specimen made of refractory castable kept at room temperature $\left(\approx 25^{\circ} \mathrm{C}\right)$ and relative air humidity $(45 \%)$ for 13 days. Two main cracks are detected by visual inspection and highlighted in red to show that both initiated on the surface and subsequently propagated in the bulk

\subsection{Evaluation of damage caused by MgO hydration using MCOD}

Approximately 100 images were acquired after $60 \mathrm{~h}$ of experiments with no need for operator intervention. Such monitoring does not require any physical contact as for IET, which makes the former likely to be in situ applied. As mentioned, one benefit of DIC analyses is the increase in the amount of gathered data related to damage effects on the surface of the analyzed samples, exemplified by the mean crack opening displacement (MCOD) field shown in Figure 5.

The MCOD fields are localized, which indicates crack networks, with no sign of a predominant crack [Figure 5]. This result implies that there are no significant boundary effects, and the assumption of an experimental RVE for the cube-shaped specimens is valid. Furthermore, a good match is observed between the top and front faces cracking for the same specimen, in particular for the common edge between the two surfaces. For an illustration and validation of the MCOD procedure, see Appendix B. 
DIC applied to in situ evaluation of cracks upon refractory castable processing
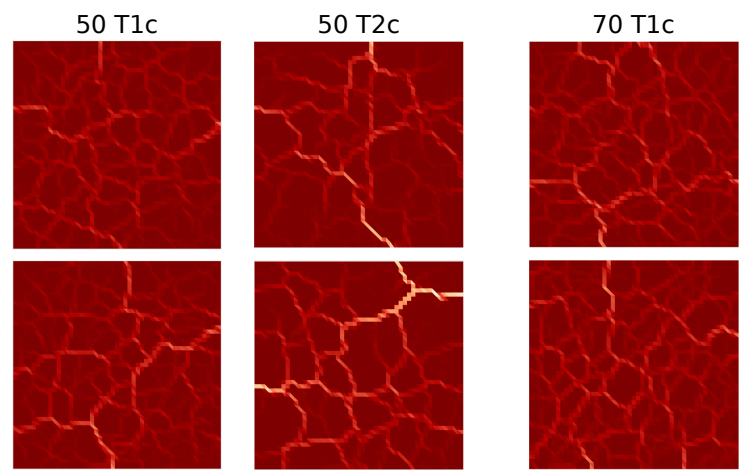

$50 \mathrm{~F} 1 \mathrm{C}$

$50 \mathrm{~F} 2 \mathrm{C}$

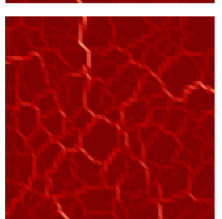

$70 \mathrm{FlC}$

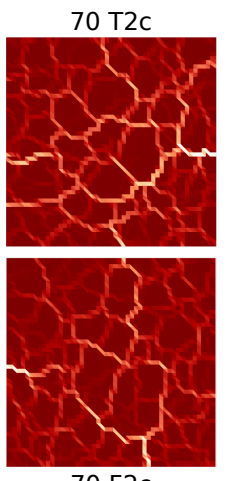

$70 \mathrm{~F} 2 \mathrm{C}$

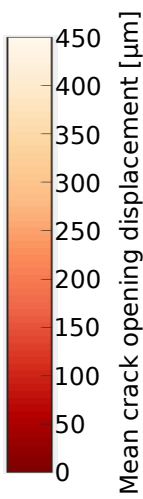

Figure 5: Mean crack opening displacement (MCOD) fields for top and front surfaces for four cubes tested at 50 and $70^{\circ} \mathrm{C}$ and $50 \%$ of relative air humidity. The fields were obtained for the 60 -hour (i.e., last) frame using a ROI of $\approx 60 \times 60 \mathrm{~mm}^{2}$

Figure 6 shows the histograms and associated cumulative frequencies for the last acquired image (after $60 \mathrm{~h}$ ) for all analyzed tests. Overall, there is a good reproducibility among different experiments at the same temperature and among surface features for the same experiment.

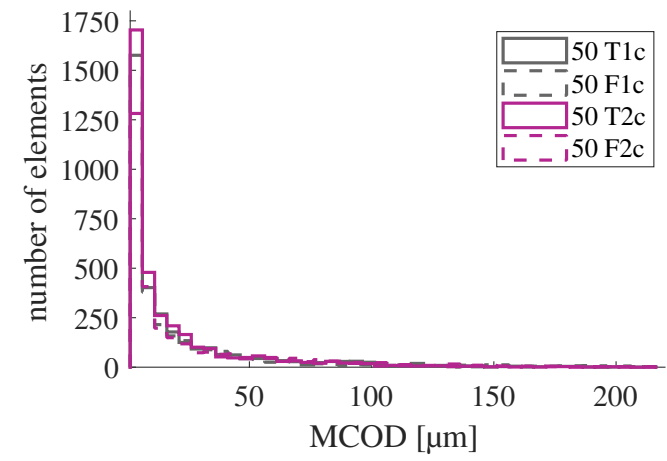

(a) Histograms $\left(T=50^{\circ} \mathrm{C}\right)$

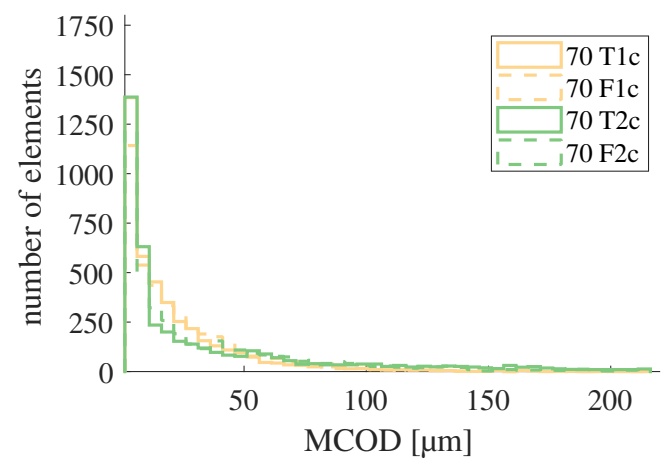

(c) Histograms $\left(T=70^{\circ} \mathrm{C}\right)$

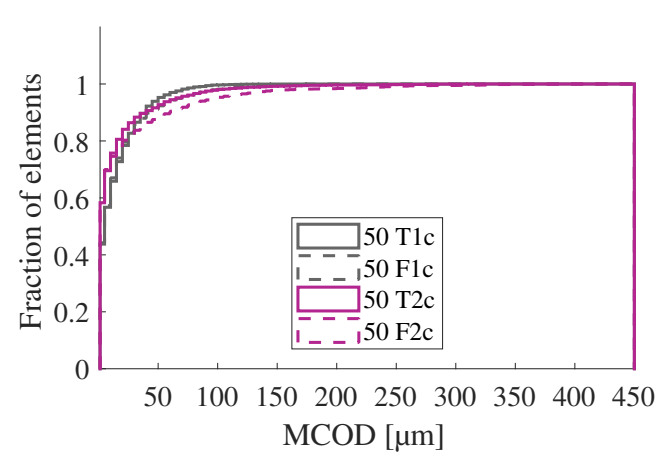

(b) Cumulative frequency $\left(T=50^{\circ} \mathrm{C}\right)$

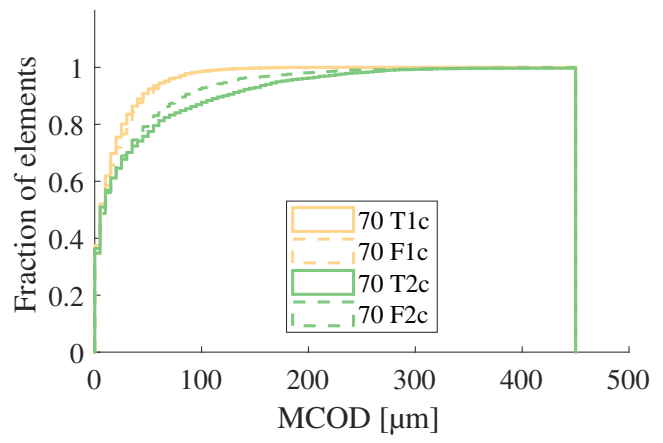

(d) Cumulative frequency $\left(T=70^{\circ} \mathrm{C}\right)$

Figure 6: Histograms of the MCOD ( $a$ and $c$ ) and their corresponding cumulative frequencies (b and d) for the two considered temperatures

The average MCOD and corresponding standard deviations after $60 \mathrm{~h}$ are reported in Table 2 . At $50^{\circ} \mathrm{C}$, the average MCOD is equal to $18 \mu \mathrm{m}$, and $29 \mu \mathrm{m}$ at $70^{\circ} \mathrm{C}$, which is consistent with the fields shown in Figure 5. The fluctuations, which are described by the standard deviations, are on average equal to $32 \mu \mathrm{m}$ at $50^{\circ} \mathrm{C}$ and $41 \mu \mathrm{m}$ at $70^{\circ} \mathrm{C}$. In both cases, the fluctuations are very high (when compared to the mean levels), which is a further indication of a very wide 
distribution of MCODs. Interestingly, the coefficient of variation (i.e., ratio of standard deviation and mean) decreases from 1.8 at $50^{\circ} \mathrm{C}$ to 1.4 at $70^{\circ} \mathrm{C}$, indicating that, the relative fluctuations decrease as the temperature increases.

\section{Table 2}

Average MCOD values and standard deviations for the final frame after $60 \mathrm{~h}$ of experiments

\begin{tabular}{c|c|c}
\hline Specimen designation & Average MCOD $[\mu \mathrm{m}]$ & Standard deviation $[\mu \mathrm{m}]$ \\
\hline \hline 50 T1c & 13 & 21 \\
\hline 50 F1c & 16 & 28 \\
\hline 50 T2c & 16 & 29 \\
\hline 50 F2c & 26 & 50 \\
\hline 70 T1c & 18 & 22 \\
\hline 70 F1c & 20 & 22 \\
\hline 70 T2c & 42 & 67 \\
\hline 70 F2c & 35 & 53 \\
\hline
\end{tabular}

Aiming at studying the development of damage frame by frame during curing and drying of the studied castable, the mean values of MCOD and the standard deviations are shown in Figure 7. The results for specimen 70 F2c indicate a peak value (for the standard deviation) that seems a non physical effect. The origin of this peak (i.e., water condensation on the window of the climatic chamber) is discussed in Appendix A. The first remarkable difference is that damage increase is higher at $70^{\circ} \mathrm{C}$ when compared to $50^{\circ} \mathrm{C}$ when no saturation is observed after $60 \mathrm{~h}$. Second, all average MCODs are less than 1 pixel, which shows that the sub-pixel resolution of DIC was crucial to properly quantify damage in such materials in which the crack openings remain very small. Both average MCOD and standard deviation show that there are differences for two surfaces of some specimen, and for different temperatures. This may be due to microstructural effects and inhomogeneities in the surface temperatures.

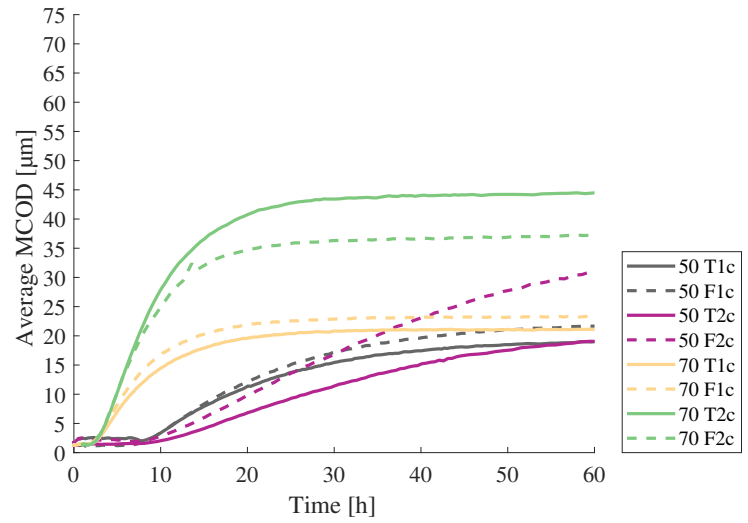

(a) Mean

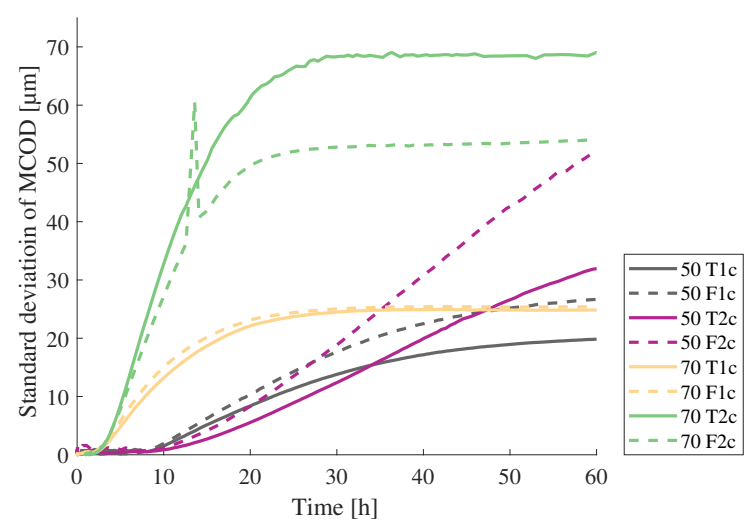

(b) Standard deviation

Figure 7: Mean (a) and standard deviation (b) MCOD for the cubic specimens at different temperatures and $50 \%$ relative air humidity

\subsection{SCD to evaluate damage growth}

DIC results obtained for cube-shaped specimens at different temperatures for a $800 \mu \mathrm{m}$ element size, are compared. The first step to compute the Surface Crack Density (SCD) is to exclude the strains caused by lighting oscillations, for example, defining a strain threshold $\epsilon_{1}^{*}$. For this step, ten images taken at the very beginning of each experiment were used to obtain the average of all standard deviations of the maximum eigen strain $\sigma\left(\bar{\epsilon}_{1}\right)$, which is a quantity that is computed at the scale of the elements. The standard uncertainties were equal to $3 \times 10^{-4}$ and $2.9 \times 10^{-4}$ for the experiments at 50 and $70^{\circ} \mathrm{C}$, respectively.

The second step is to include in $\epsilon_{1}^{*}$, the strains related to the expansion of the $\mathrm{MgO}$ containing phases before damage inception. This inclusion is made using a factor $A$ defined by the user. The effect of different values of $A$ (varying from two to seven) on the SCD is shown in Figure 8(a). 


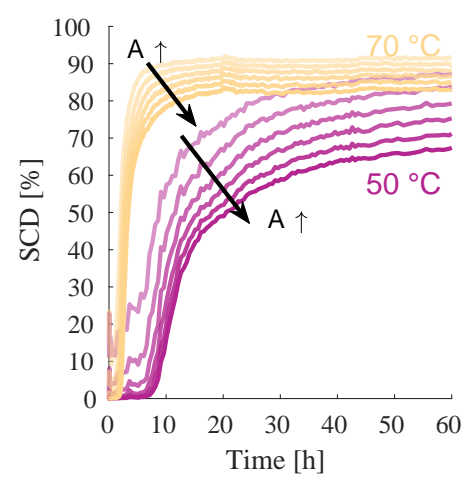

(a)

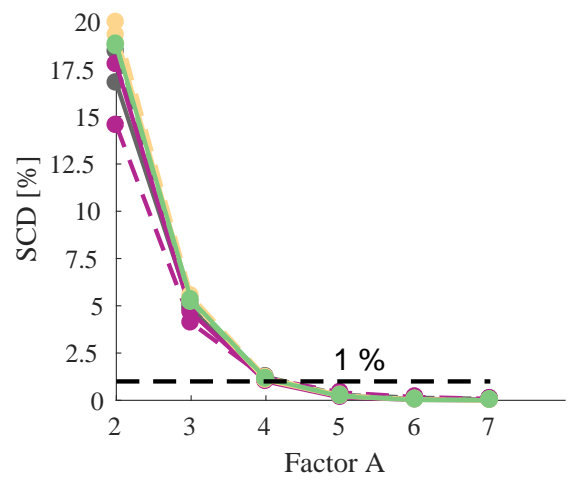

(b)

Figure 8: Surface crack densities as functions of parameter $A$ (see Figure 7 for sample color code). (a) SCDs for the top surface of cubes tested at $50^{\circ} \mathrm{C}$ and $70^{\circ} \mathrm{C}$ using different values of $A$ to estimate the $\epsilon_{1}^{*}$ threshold (samples 50 T1c and 70 T2c). (b) Mean value of SCD for the 10 initial images of each experiment to estimate $A$. The black dashed line indicates the selected level

Small $A$ values result in an initial crack density at the beginning of the experiments before actual crack initiation [Figure 8(a)]. Conversely, high $A$ values lead to a decrease in the SCD, mainly at the end of experiments. It is not possible to estimate a specific level for damage at the end of the tests because it depends on $A$. However, one can state that the damage level for the castable tested at $70^{\circ} \mathrm{C}$ is higher than at $50^{\circ} \mathrm{C}$ for all considered $A$ values [Figure $8(\mathrm{a})$ ].

The mean SCD for the initial 10 images of each experiment was computed to help to choose the most suitable $A$ parameter [Figure 8(b)]. A high $A$ factor flattens out the curve profile, which is a trivial condition of no elements considered damaged and for that reason, the first value of $A$ that resulted in mean SCD values less than $1 \%$ for the first ten image group was selected, i.e., $A=5$ [Figure 8(b)]. The thresholds $\epsilon_{1}^{*}$ estimated for the experiments at $50^{\circ} \mathrm{C}$ and $70^{\circ} \mathrm{C}$ were $1.5 \times 10^{-3}$ (i.e., $\mathrm{MCOD}=1.3 \mu \mathrm{m}$ ) and $1.4 \times 10^{-3}$ (i.e., $\mathrm{MCOD}=1.2 \mu \mathrm{m}$ ), respectively.

The SCD for the surfaces of the cubes evaluated at $50^{\circ} \mathrm{C}$ and $70^{\circ} \mathrm{C}$ are shown in Figure 9. The change of the

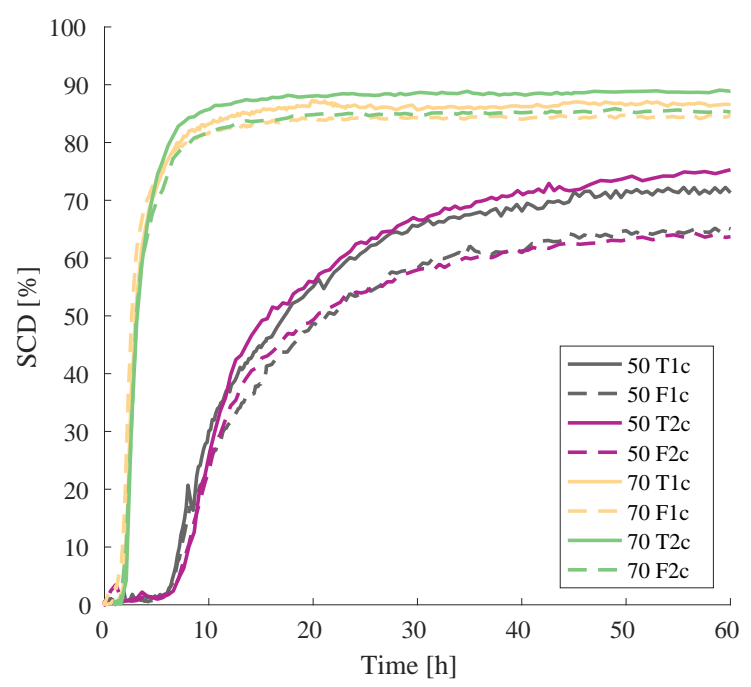

Figure 9: Surface crack density obtained by DIC during brucite formation in cube-shaped specimens for two different temperatures and $50 \%$ relative air humidity

SCD follows a logistic curve (sigmoidal shape), similar to those for the MgO hydration kinetics obtained by other 
techniques [10]. The increase in temperature speeds up the hydration kinetics, the SCD onset, and the final damage levels are achieved earlier for the experiments carried out at higher temperatures. The reproducibility of the results for analogous surfaces is very good and validates the experimental protocol. The front surfaces of the specimens exhibited less damage than the top ones for the lower temperature, but further investigation is needed to determine the causes of such a phenomenon.

The overall trends of Figures 7 and 9 are identical, namely, after an initial incubation time, all quantities start to increase rather fast and then tend to flatten out. However, the characteristic times associated with such phenomena are different for SCD and MCOD data. The former flattens out faster than the latter. This observation shows that many cracks are generated at the beginning of the damage process, growing fast on the surface, and then saturating in terms of their number. However, this situation does not mean that the damage process ceased. The fact that MCOD data still increase means that the crack openings augment as well, which may indicate that in-depth propagation still occurs, leading to larger crack openings on the surface. This observation is confirmed by the results of Figure 4 that show gradual in-depth propagation. Furthermore, the number of generated cracks may be related to the temperature effect since the SCD values for specimens tested at the same temperature (i.e., $50 * 1 \mathrm{c}$ and $50 * 2 \mathrm{c}$ saturated at $\approx 65 \%$, and 70 $* 1 \mathrm{c}$ and $70 * 2 \mathrm{c}$ at $\approx 85 \%$, where $*$ stands for $\mathrm{F}$ or $\mathrm{T})$ are very close.

\subsection{Comparison between IET and DIC}

The bar-shaped specimens used for DIC analyses are designated as $50 \mathrm{~T} 1 \mathrm{~b}$ and $50 \mathrm{~T} 2 \mathrm{~b}$, and those for IET, 50 $\mathrm{T} 3 \mathrm{~b}$ and $50 \mathrm{~T} 4 \mathrm{~b}$. The four samples were produced from the same batch, only cast in different cavities of the silicone mold. The four bars were placed inside the climatic chamber at $50^{\circ} \mathrm{C}$ and $50 \%$ air humidity. Specimens $50 \mathrm{~T} 1 \mathrm{~b}$ and 50 $\mathrm{T} 2 \mathrm{~b}$ were kept there for image acquisition. Samples $50 \mathrm{~T} 3 \mathrm{~b}$ and $50 \mathrm{~T} 4 \mathrm{~b}$ were frequently withdrawn from the climatic chamber for carrying out IET measurement, which lasted $\approx 30$ minutes, and they were kept in the chamber between measurements.

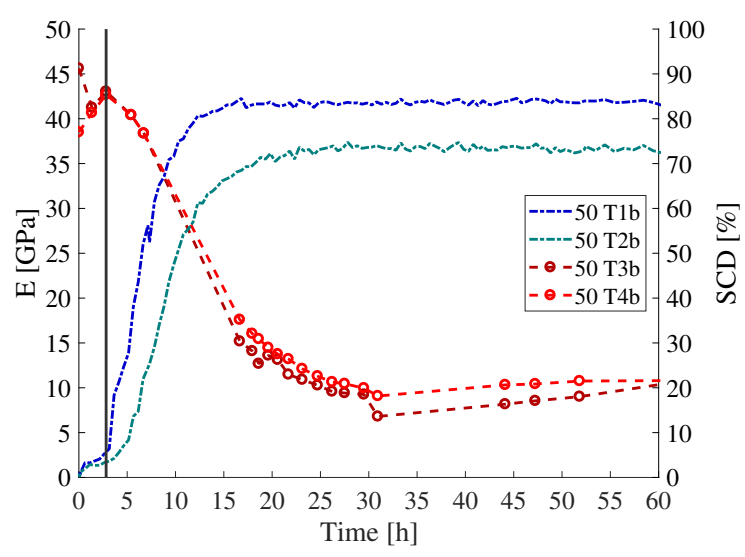

(a)

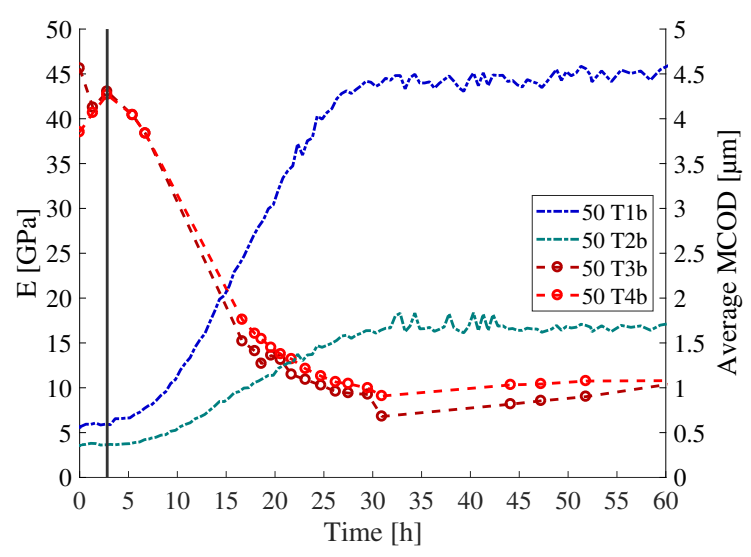

(b)

Figure 10: $\mathrm{SCD}(\mathrm{a})$ and MCOD (b) (specimen designation: $50 \mathrm{~T} 1 \mathrm{~b}$ and $50 \mathrm{~T} 2 \mathrm{~b}$ ) compared to IET data (specimen designation: $50 \mathrm{~T} 3 \mathrm{~b}$ and $50 \mathrm{~T} 4 \mathrm{~b}$ ) during curing and drying of the castable samples at $50^{\circ} \mathrm{C}$ and $50 \%$ humidity

The damage caused by magnesia hydration affects both the Young's modulus $(E)$ measured by IET, as well as the MCOD and SCD obtained by DIC analyses [Figure 10]. The solid gray line indicates that the onset for Young's modulus decrease matches with that of the SCD increase, yet the onset of MCOD is more gradual. Conversely, the saturation of MCOD and Young's modulus are very close, whereas that of SCD occurs earlier. The causes of such phenomena are detailed in the discussion about Figure 11 hereafter. The reader's attention is directed to the fact that DIC results captured distinct parts of the Young's modulus changes (i.e., fast SCD increase and saturation while MCOD was still increasing), which was not distinguishable by IET. This aspect reinforces DIC as a better technique to study the hydration kinetics.

IET and DIC results were compared by plotting the SCD and average MCOD as functions of the macroscopic estimation of damage [47], namely, $D=1-E / E_{\max }$ were $E_{\max }$ is the maximum Young's modulus, as shown in Figure 11. For samples $50 \mathrm{~T} 3 \mathrm{~b}$ and $50 \mathrm{~T} 4 \mathrm{~b}$, the Young's modulus changes were very close, as stated in Figure 10, 
and the average value of each measurement was used to compute the macroscopic damage variable $D$. Conversely, the DIC results (samples $50 \mathrm{~T} 1 \mathrm{~b}$ and $50 \mathrm{~T} 2 \mathrm{~b}$ ) are plotted separately. Figure 10 shows that the SCD values saturate while the damage parameter continues to increase, which means that damage keeps growing due to additional crack openings for the same network (i.e., the same number of damaged elements). This result shows that in the present case, macroscopic damage is due to a combined effect of multiple cracking events (characterized by the crack density), and the fact that cracks open more evenly as the network saturated in terms of crack density. This additional opening displacement is due to in-depth propagation [Figure 4].

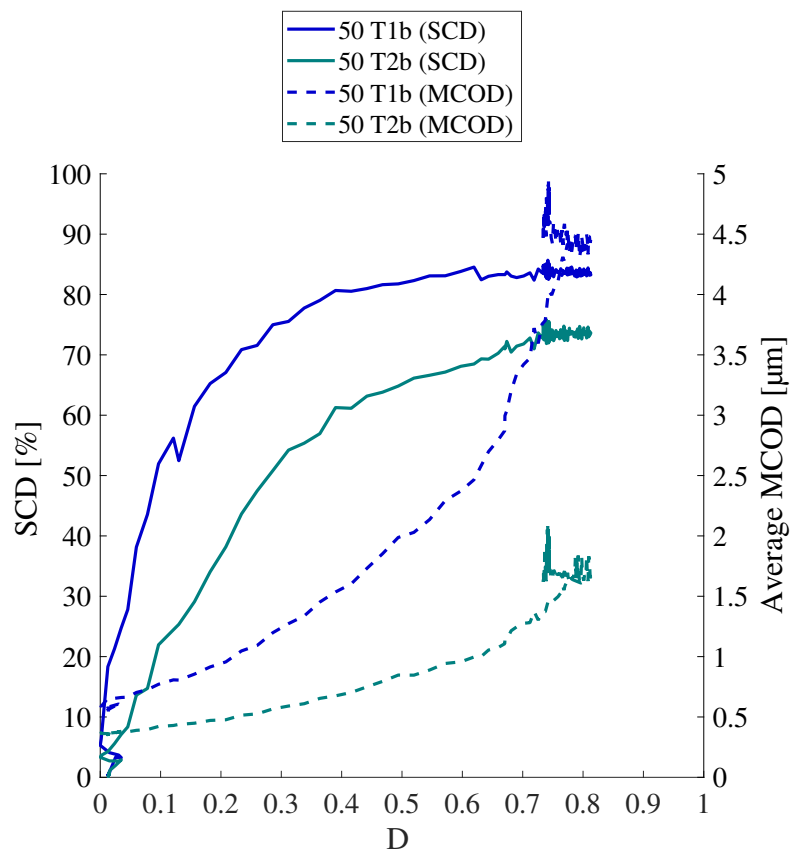

Figure 11: SCD and average MCOD for the bar-shaped specimens (50 T1b and $50 \mathrm{~T} 2 \mathrm{~b}$ ) versus the macroscopic damage $D$ (evaluated from samples (50 T3b and $50 \mathrm{~T} 4 \mathrm{~b}$ )

\subsection{DIC results for different specimen geometries}

In this section, a qualitative comparison between DIC results obtained for both sample geometries is presented. Figure 12 shows the MCOD fields for one face of a cubic-specimen (50 T2c) and one bar-shaped sample (50 T1b). For the latter, the main crack was usually generated parallel to its most extended edges [Figure 12(a)], which is most likely related to the slender shape of the bars required by IET. This observation does not apply for cube-shaped samples [Figures 12(b) and 5]. 


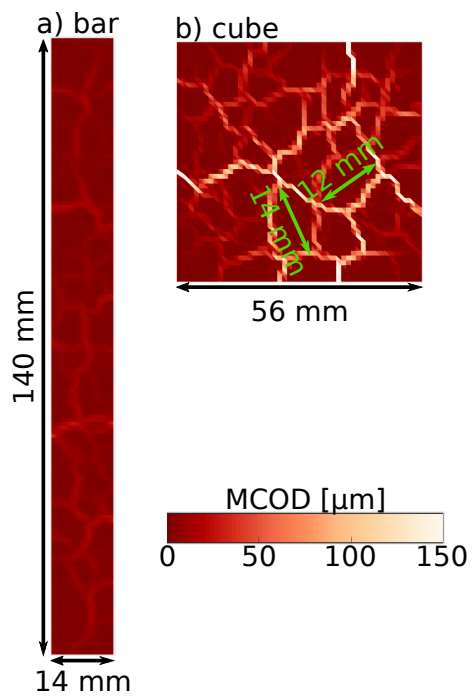

Figure 12: MCOD fields for $50 \mathrm{~T} 1 \mathrm{~b}(\mathrm{a})$ and $50 \mathrm{~T} 2 \mathrm{c}(\mathrm{b})$ samples after $60 \mathrm{~h}$ in the climatic chamber at $50^{\circ} \mathrm{C}$ and $50 \%$ air humidity. The color map range was truncated (up to $150 \mu \mathrm{m}$ ) to make the crack openings in the bar-specimen visible

Additionally, the $50 \mathrm{~T} 2 \mathrm{c}$ samples showed higher MCOD levels than the $50 \mathrm{~T} 1 \mathrm{~b}$ ones, which may be related to the boundary effects. The size of large clusters presenting MCODs values close to zero on the cube surface, such as those indicated by green arrows (12 $\mathrm{mm}$ and $14 \mathrm{~mm}$ in length), have almost the same size as the bar width, which makes the hypothesis of an experimental RVE questionable for bars containing large aggregates $(\approx 6 \mathrm{~mm})$.

There is also a clear difference between the average MCOD and SCD profiles when the bar-shaped specimen and the cubes $(50 \mathrm{~T} 1 \mathrm{c}, 50 \mathrm{~F} 1 \mathrm{c}, 50 \mathrm{~T} 2 \mathrm{c} 50 \mathrm{~F} 2 \mathrm{c})$ are compared under the same environmental conditions [Figure 13]. MCOD values are significantly smaller for the bar than cubes, whereas the SCD levels are higher for the bar than the cubes. This difference may be attributed to the fact that the bar-shaped specimen is not yet an experimental RVE. Consequently, it is advisable to use sample sizes greater, which means at least ten times the size of the largest aggregates, to study the refractory castables. This observation is an example of the benefits in gathering DIC information.

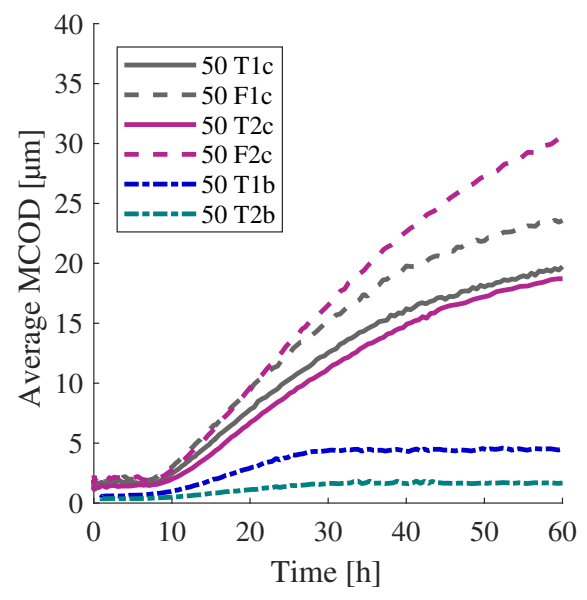

(a)

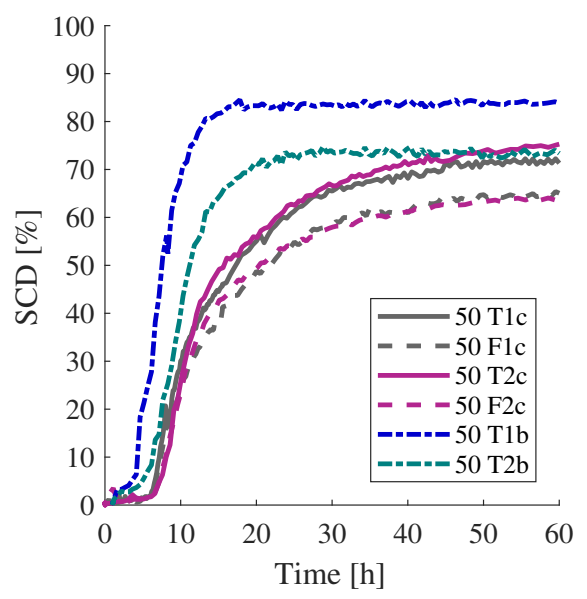

(b)

Figure 13: MCOD (a) and SCD (b) profiles for cubic specimens (50 T1c, $50 \mathrm{~F} 1 \mathrm{c}, 50 \mathrm{~T} 2 \mathrm{c}$ and $50 \mathrm{~F} 2 \mathrm{c}$ ) and bar-shaped samples (50 T1b and $50 \mathrm{~T} 2 \mathrm{~b}$ ) at $50^{\circ} \mathrm{C}$ and $50 \%$ relative air humidity 


\section{Conclusion}

An in-house climatic chamber with glass windows was built to evaluate the in situ development of crack networks via DIC. The in situ applicability of DIC is a key aspect for damage quantification at different temperatures via Mean Crack Opening Displacement (MCOD) fields and Surface Crack Density (SCD). The importance of using specimens with a size compatible with a Representative Volume Element was pointed out by comparing the crack networks generated by $\mathrm{MgO}$ hydration in high alumina castables for cubic and bar-shaped specimens, the latter being required for carrying out Impulse Excitation (IE) analyses.

One immediate advantage of DIC over IET is that the former provides in situ evaluations as the images are captured without taking the specimen out of the climatic chamber, thereby making possible the automation of experiments. Besides, DIC supplies more information about damage development by highlighting its growth over time due to increased crack density (SCD) and crack openings (MCOD) for crack networks on the monitored surfaces.

Tomography scans showed that such cracks initiated on the surface, and propagated toward the center of the specimens in an intergranular way. This result validates the use of DIC as a tool to study the MgO hydration using surface images. It also shows that ex situ scans could be carried out to fully quantify damage via digital volume correlation.

Aiming at studying damage generated by $\mathrm{MgO}$ hydration, the average MCOD and its standard deviation were computed frame by frame. The network saturation is faster at $70^{\circ} \mathrm{C}$ than at $50^{\circ} \mathrm{C}$, which was hardly reached after $60 \mathrm{~h}$ for the latter. These results showed fair reproducibility among similar experiments. Conversely, the SCD results were more reproducible. SCD values flattened out faster than MCOD data, which accounted for crack density increase and crack opening displacements as in-depth propagation was still occurring.

Cube-shaped specimens larger than bar-shaped samples were used and highlighted the importance of a satisfactory experimental RVE size, as no boundary effects were observed for the cubes. When comparing the results of IET to those of DIC, it indicated the increase in damage quantified by SCD and MCOD associated with the reduction of macroscopic Young's modulus. It was observed that macroscopic damage still increased with average MCOD, even though the SCD had saturated. This observation showed that MCOD data better captured the main features of the crack networks observed herein. Combined with the results obtained by tomography scans, all these outcomes validate using DIC for cases such as those analyzed in this work. The MCOD fields are very useful to quantify crack networks (e.g., damage localization), which is an additional advantage of DIC over IET that provides one (macroscopic) damage value for the entire specimen.

\section{Acknowledgements}

This study was financed in part by the Coordenação de Aperfeiçoamento de Pessoal de Nível Superior - Brasil (CAPES) - Finance Code 001. V. S. would also like to thank CAPES for the PDSE grant \# 8881.188511/2018-01 used during the internship at LMT. The authors would also like to thank FIRE (Federation for International Refractory Research and Education) for the partial financial support of this research. This study was also partially supported by the FAPESP-CNRS SPRINT project, grant \#2018/15266-0, São Paulo Research Foundation (FAPESP). 


\section{Appendix A: Effect of water droplet on MCOD fields}

A (spurious) peak in the results of mean and standard MCOD was observed in Figures 7(a-b), which was caused by water droplets onto the window of the climatic chamber. Water had condensed on the walls inside the climatic chamber and dropped on the glass window. The defogger keeps the window warm but not warm enough to dry out the droplets quickly, which act as lenses changing the optical path of the pixels behind them. This effect results in localized "optical" strains, which consequently generated false MCOD values [Figure 14].

Figure 14 shows the images prior to the water droplets, when they were present, after evaporation and their artifactual effect on MCOD fields. It is interesting to note that as soon as the droplets disappeared, their deleterious effect vanished as well. Gray level correction procedures [27], not applied in this study, may be implemented to mitigate such effects.

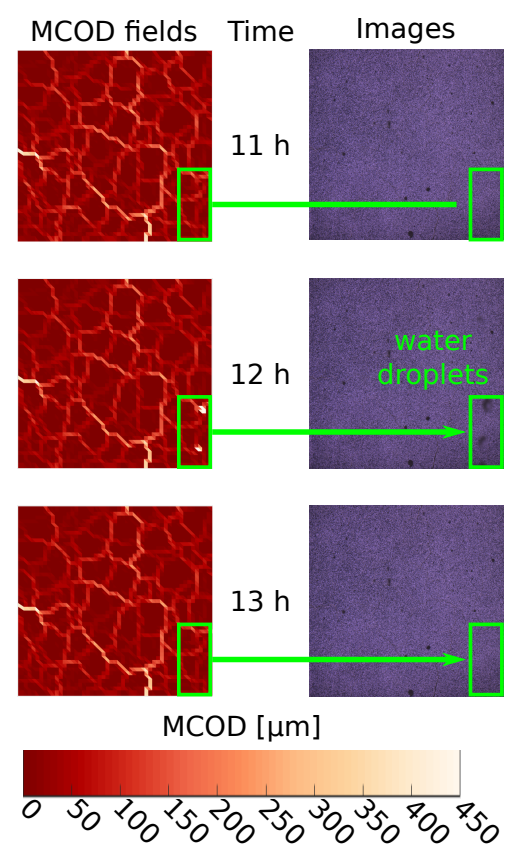

Figure 14: MCOD fields for $70 \mathrm{~F} 2 \mathrm{c}$ sample. The images analyzed (ROI size $\approx 60 \times 60 \mathrm{~mm}^{2}$ ) show the artifactual effect on MCOD fields caused by water droplets on the window of the climatic chamber. The color-map range of the field was limited to $450 \mu \mathrm{m}$ because the MCOD caused by the droplets is very high, which masks the cracks

\section{Appendix B: Illustration and validation of MCOD evaluation}

To illustrate and validate the MCOD results, the deformed mesh amplified 20 times is shown in Figure 15(a). The corresponding nodal displacement vectors of the upper right corner are reported in Figure 15(b) and the manual measurements of crack opening displacement in Figure 15(c) for the same region, is also shown. The deformed elements in Figure 15(a) follow the crack path, and there are virtually undeformed elements in adjacent positions to the crack path. There are regions in Figure 15(b) with different displacement directions among them; in fact, such regions are apart from each other, as illustrated by the vector field. This characteristic behavior is a consequence of cracking, which makes these regions delimited by the crack network. Furthermore, the undeformed mesh in the selected area shows that not more than one crack is present in one element, which is a pre requisite for the MCOD to be approximated by Equation (10).

Some manual evaluations of crack opening displacements using the GNU Image Manipulation Program (GIMP) are reported in Figure 15(c) for the upper right corner of sample 50 F2c (see Figure 5 for the corresponding MCOD field). The values are close to those found in MCODs, as shown in Table 3, which validates the methodology. It is worth noting that the boundaries of the crack are difficult to pinpoint very precisely, and only normal openings can be assessed in such manual measurements. The MCOD analysis easily overcomes these challenges for cases in which 


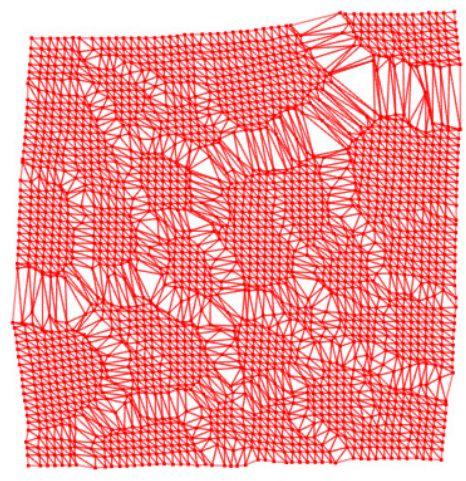

(a)

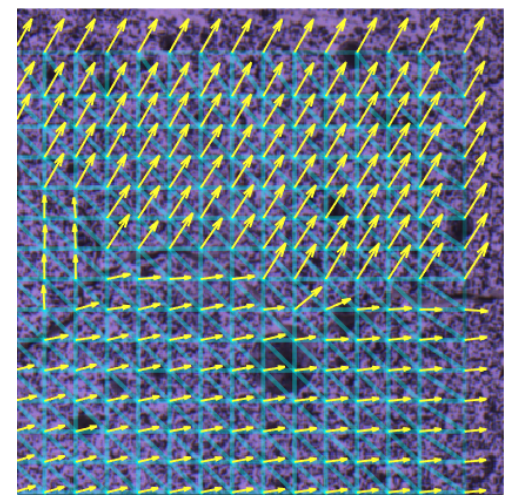

(b)

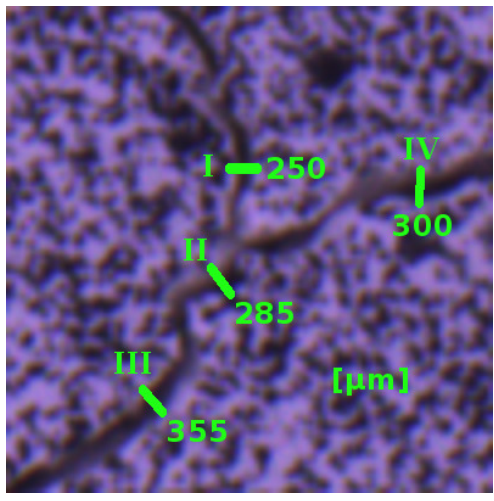

(c)

Figure 15: (a) Deformed mesh amplified 20 times for the entire surface of 50 F2c sample. (b) Details of the undeformed mesh and nodal displacement vectors for the upper right corner laid over the deformed image. (c) Manual measurement of crack opening displacements in the deformed image to be compared to MCOD values reported in Figure 5

the assumption of one crack per element is valid. The RMS difference between the two types of estimates is less than $60 \mu \mathrm{m}$ (i.e., 1.2 pixel), which is considered very satisfactory, given the fact that the manual evaluation is based on pixel-data. Conversely, as the standard MCOD uncertainty is close to $1.3 \mu \mathrm{m}$ (i.e., 0.025 pixel), it indicates that DIC is more accurate at the scale of the displacement discretization.

\section{Table 3}

Crack opening displacement obtained by direct measurement (using GIMP) and MCOD data via DIC

\begin{tabular}{|c|c|c|}
\hline Measurement & GIMP $[\mu \mathrm{m}]$ & DIC $[\mu \mathrm{m}]$ \\
\hline I & 355 & 252 \\
\hline II & 285 & 233 \\
\hline III & 300 & 326 \\
\hline IV & 250 & 298 \\
\hline
\end{tabular}




\section{References}

[1] W. Lee, W. Vieira, S. Zhang, K. Ahari, H. Sarpoolaky, C. Parr, Castable refractory concretes, International Materials Reviews 46 (3) (2001) 145-167. doi:10.1179/095066001101528439.

[2] M. Rigaud, N. Zhou, Major trends in refractories industry at the beginning of the 21st century, China's Refractories 11 (2) (2002) 3-8.

[3] H. Sarpoolaky, S. Zhang, B. B. Argent, W. E. Lee, Influence of grain phase on slag corrosion of low-cement castable refractories, Journal of the American Ceramic Society 84 (2) (2001) 426-34.

[4] R. A. Landy, Magnesia refractories, Mechanical Engineering-New York and Basel-Marcel Dekker Then Crc Press/Taylor and Francis 178 (2004) 109

[5] H. S. Tripathi, B. Mukherjee, S. Das, M. K. Haldar, S. K. Das, A. Ghosh, Synthesis and densification of magnesium aluminate spinel: effect of $\mathrm{MgO}$ reactivity, Ceramics International 29 (8) (2003) 915-918.

[6] M. A. L. Braulio, L. R. M. Bittencourt, V. C. Pandolfelli, Magnesia grain size effect on in situ spinel refractory castables, Journal of the European Ceramic Society 28 (15) (2008) 2845-2852.

[7] G. K. Layden, G. Brindley, Kinetics of vapor-phase hydration of magnesium oxide, Journal of the American Ceramic Society 46 (11) (1963) $518-522$.

[8] P. Brandão, G. Goncalves, A. Duarte, Mechanisms of hydration/carbonation of basic refractories, Refractories Applications 3 (3) (1998) 6-7.

[9] P. Brandão, G. Goncalves, A. Duarte, Mechanisms of hydration/carbonation of basic refractories. Pt. 2. Investigation of the kinetics of formation of brucite in fired basic bricks, Refractories Applications 3 (2) (1998) 9-11.

[10] R. Salomão, V. C. Pandolfelli, The role of hydraulic binders on magnesia containing refractory castables: calcium aluminate cement and hydratable alumina, Ceramics International 35 (8) (2009) 3117-3124.

[11] T. M. Souza, M. A. L. Braulio, A. P. Luz, P. Bonadia, V. C. Pandolfelli, Systemic analysis of MgO hydration effects on alumina-magnesia refractory castables, Ceramics International 38 (5) (2012) 3969-3976.

[12] L. F. Amaral, I. R. Oliveira, R. Salomão, E. Frollini, V. C. Pandolfelli, Temperature and common-ion effect on magnesium oxide (MgO) hydration, Ceramics International 36 (3) (2010) 1047 - 1054. doi : https://doi.org/10.1016/j.ceramint.2009.12.009.

[13] R. Salomão, L. R. M. Bittencourt, V. C. Pandolfelli, A novel approach for magnesia hydration assessment in refractory castables, Ceramics International 33 (5) (2007) 803-810.

[14] T. M. Souza, A. P. Luz, T. Santos, D. C. Gimenes, M. M. Miglioli, A. Correa, V. C. Pandolfelli, Phosphate chemical binder as an anti-hydration additive for $\mathrm{Al}_{2} \mathrm{O}_{3}-\mathrm{MgO}$ refractory castables, Ceramics International 40 (1) (2014) 1503-1512.

[15] Standard test method for dynamic young's modulus, shear modulus, and poisson's ratio for advanced ceramics by sonic resonance, Tech. rep., ASTM International, West Conshohocken (2013).

[16] T. M. Souza, A. P. Luz, M. A. Braulio, C. Pagliosa, V. C. Pandolfelli, Acetic acid role on magnesia hydration for cement-free refractory castables, Journal of the American Ceramic Society 97 (4) (2014) 1233-1241.

[17] T. Santos, A. P. Luz, C. Pagliosa, V. C. Pandolfelli, $\mathrm{Mg}(\mathrm{OH})_{2}$ nucleation and growth parameters applicable for the development of $\mathrm{MgO}$-based refractory castables, Journal of the American Ceramic Society (2016).

[18] Standard test method for dynamic Young's modulus, shear modulus, and Poisson's ratio by impulse excitation of vibration, Tech. rep., ASTM International, West Conshohocken (2015).

[19] R. Telle, N. Traon, T. Tonnesen, The understanding of the microstructural changes of refractory castables after thermal shocks through damping measurements, Refractories Worldforum 4 (1) (2012) 119-124.

[20] R. Salomão, A. D. V. Souza, P. H. L. Cardoso, A comparison of $\mathrm{Al}(\mathrm{OH})_{3}$ and $\mathrm{Mg}(\mathrm{OH})_{2}$ as inorganic porogenic agents for alumina, InterceramInternational Ceramic Review 64 (4-5) (2015) 193-199.

[21] S. McNeill, W. Peters, M. Sutton, Estimation of stress intensity factor by digital image correlation, Engineering Fracture Mechanics 28 (1) (1987) 101-112.

[22] M. A. Sutton, W. Zhao, S. R. McNeill, J. D. Helm, R. S. Piascik, W. T. Riddell, Advances in fatigue crack closure measurement and analysis: Second Volume, ASTM STP 1343, West Conshohocken, 1999, Ch. Local crack closure measurements: Development of a measurement system using computer vision and a far-field microscope, pp. 145-156.

[23] J. Abanto-Bueno, J. Lambros, Investigation of crack growth in functionally graded materials using digital image correlation, Engineering Fracture Mechanics 69 (2002) 1695-1711.

[24] P. Forquin, L. Rota, Y. Charles, F. Hild, A method to determine the toughness scatter of brittle materials, International Journal of Fracture 125 (1) (2004) 171-187.

[25] L. Robert, F. Nazaret, T. Cutard, J. J. Orteu, Use of 3D digital image correlation to characterize the mechanical behavior of a fiber reinforced refractory castable, Experimental Mechanics 47 (6) (2007) 761-773.

[26] J. Rupil, S. Roux, F. Hild, L. Vincent, Fatigue microcrack detection with digital image correlation, The Journal of Strain Analysis for Engineering Design 46 (6) (2011) 492-509.

[27] F. Hild, S. Roux, Digital image correlation, in: P. Rastogi, E. Hack (Eds.), Optical Methods for Solid Mechanics. A Full-Field Approach, Wiley-VCH, Weinheim (Germany), 2012, pp. 183-228.

[28] D. B. D. Stafuzza, J. A. Rodrigues, D. Miyaji, R. B. Canto, Application of the digital image correlation technique to the fracture energy method for refractory concretes, in: Congresso Brasileiro de Engenharia e Ciência dos Materiais - $20^{\circ}$ CBECiMat, Joinville, 2012, pp. 2300-2307, (In Portuguese).

[29] Y. Belrhiti, O. Pop, A. Germaneau, P. Doumalin, J. C. Dupré, H. Harmuth, M. Huger, T. Chotard, Investigation of the impact of micro-cracks on fracture behavior of magnesia products using wedge splitting test and digital image correlation, Journal of the European Ceramic Society 35 (2) (2015) 823-829.

[30] R. G. M. Saracura, R. B. Canto, V. C. Pandolfelli, N. Schmitt, F. Hild, Surface crack network detection on MgO-based refractory castable by digital image correlation, China's Refractories 24 (1) (2015) 32-37.

[31] R. Vargas, J. Neggers, R. B. Canto, J. A. Rodrigues, F. Hild, Analysis of wedge splitting test on refractory castable via integrated DIC, Journal 
of the European Ceramic Society 36 (16) (2016) 4309-4317.

[32] F. Hild, A. Bouterf, S. Roux, Damage measurements via DIC, International Journal of Fracture 191 (1-2) (2015) 77-105.

[33] F. Benboudjema, T. Mauroux, P. Turcry, A. Ait-Mokthar, O. Deves, Experimental analysis of drying shrinkage cracking in coating mortars by digital image correlation, in: Mechanics and Physics of Creep, Shrinkage, and Durability of Concrete: A Tribute to Zdeněk P. Bažant: Proceedings of the Nineth International Conference on Creep, Shrinkage, and Durability Mechanics (CONCREEP-9), September 22-25, 2013 Cambridge, Massachusetts, ASCE Publications, 2013, p. 235.

[34] R. G. M. Saracura, Study of cracks on refractory castables during its curing added by digital image correlation technique, Master's thesis, Universidade Federal de São Carlos, Brazil, (In Portuguese) (2015).

[35] M. A. Sutton, J. J. Orteu, H. Schreier, Image correlation for shape, motion and deformation measurements: Basic concepts, theory and applications, Springer Science \& Business Media, 2009.

[36] Standard test method for monotonic compressive strength of advanced ceramics at ambient temperature, Tech. rep., ASTM International (2015).

[37] Standard test method for measuring consistency of castable refractory using a flow table, Tech. rep., ASTM International (2018).

[38] J. Lemaitre, J. Chaboche, Mechanics of Solid Materials, Cambridge University Press, Cambridge (UK), 1990.

[39] P. Leplay, O. Lafforgue, F. Hild, Analysis of asymmetrical creep of a ceramic at $1350{ }^{\circ} \mathrm{C}$ by Digital Image Correlation, Journal of the American Ceramic Society 98 (7) (2015) 2240-2247.

[40] P. J. Burt, Local correlation measures for motion analysis: a comparative study, in: Proc. Pattern Recognition and Image Processing Conf., Las Vegas, 1982, 1982.

[41] M. A. Sutton, W. J. Wolters, W. H. Peters, W. F. Ranson, S. R. McNeill, Determination of displacements using an improved digital correlation method, Image and Vision Computing 1 (3) (1983) 133 - 139. doi:DOI:10.1016/0262-8856 (83)90064-1.

URL http://www. sciencedirect.com/science/article/B6V09-4903X4F-2/2/647e85f196f2be3061063eb084931cd1

[42] M. A. Sutton, S. R. McNeill, J. D. Helm, Y. J. Chao, Advances in two-dimensional and three-dimensional computer vision, in: Photomechanics, Vol. 77 of Topics in Applied Physics, 2000, pp. 323-372.

[43] G. Besnard, F. Hild, S. Roux, "Finite-Element" displacement fields analysis from digital images: Application to Portevin-Le Chatelier bands, Experimental Mechanics 46 (6) (2006) 789-803.

[44] H. Leclerc, J. Périé, S. Roux, F. Hild, Integrated digital image correlation for the identification of mechanical properties, Vol. LNCS 5496, Springer, Berlin (Germany), 2009, pp. 161-171.

[45] A. Vakulenko, M. Kachanov, Continuum theory of medium with cracks, Isv. AN SSSR, Mekh. Tverdogo Tela 4 (1971) $159-166$.

[46] H. Leclerc, J. Neggers, F. Mathieu, S. Roux, F. Hild, Correli 3.0, IDDN.FR.001.520008.000.S.P.2015.000.31500 (2015).

[47] J. Lemaitre, A Course on Damage Mechanics, 2nd Edition, Springer-Verlag, Berlin (Germany), 1992. doi: 10.1007/978-3-642-18255-6. 